\title{
Power Purchase Model of Provincial Grids Based on Diverse Energy Coordination Hedging Optimization
}

\author{
Dunnan Liu', Yujie Xu1, Weimin Zeng², Jiangping Liu², Min Fan², Xinming Liu' \\ ${ }^{1}$ School of Economics and Management, North China Electric Power University, Beijing, China \\ ${ }^{2}$ Hubei Provincial Electric Power Company Power Exchange Center, Wuhan, China \\ Email: liudunnan@163.com, xuyujie0802@163.com, zengwm@hb.sgcc.com.cn
}

Received December 2013

\begin{abstract}
Under the background of energy conservation, the grid companies should give priority to consumptive hydropower, wind power and other clean electricity to fulfill their social responsibility and promote the carbon emission reduction in power industry. But under the current power purchase mode, grid companies must first perform the contract. This is extremely uneconomical and not environmentally friendly. Based on hedging theory, this paper proposes a power purchase optimization model using the strategy of "compression and compensation". If outer price is lower than the contract price, the grid can compress contract power appropriately, leaving more space for purchasing electricity; if outer price is not attractive enough, the grid should timely improve contract proportion, compensating the deviations of contract caused by "compression". Based on the strategy of "compression and compensation", it can effectively reduce the abandoned wind and water, enhance the economic and social benefits of provincial power grid.
\end{abstract}

\section{Keywords}

Power Purchase Optimization; Hedging; "Compression and Compensation"; Large-Scale System Decomposition-Coordination

\section{Introduction}

Through optimization of electricity purchase, it can reduce the phenomenon of abandoned water in wet season and increase the proportion of hydropower, wind power and other clean energy. It can also ensure security of electricity supply and create the optimal operating efficiency. Currently, studies on the optimization of power purchase focused on reasonable purchase order, purchase optimization of new energy sources such as wind power, considering power purchase tariff, and so on [1]-[3]. However, research on optimizing the contract execution case to adjust the size of the monthly purchase of electricity is still in its infancy. Focusing on the power adjustment programs and contract amount, this paper gives a different distribution scheme under the monthly power purchase decisions.

How to cite this paper: Liu, D.N., et al. (2014) Power Purchase Model of Provincial Grids Based on Diverse Energy Coordination Hedging Optimization. Journal of Power and Energy Engineering, 2, 463-469.

http://dx.doi.org/10.4236/ipee.2014.24062 


\section{Monthly Purchase Optimization Principle}

\subsection{Background of Purchase Optimization}

Currently, the provincial power grids usually implement the task of electricity contract priority. Only when the contract can't meet the load requirements of electricity, power grids will seek electricity trade passively, which is extremely uneconomical and not environmentally friendly. Traditional purchase strategies can't meet the power purchase of hydropower, wind power and other clean resources in consumptive surplus period, resulting in severe wind and water abandoned. Therefore, the study of how to maximize the proportion of clean energy access in the monthly purchase, promoting regional power allocation of resources to achieve the best efficiency power purchase optimization is very important.

To ensure the security of electricity supply, the grids usually sign power purchase contracts with power plants and they must complete the annual purchase task successfully. However, power companies are allowed to have a certain amount of floating in space when implementing the monthly contract plan. The existence of this floating space makes the grid companies can dominate the purchase right flexible. Therefore, in resource-rich seasons or situations of cheap electricity for sale, provincial grid can reduce electricity purchase contracts and make use of compressed space to buy such a cheap clean energy; Meanwhile, in resource-poor seasons or when outer provinces have no cheap power, provincial grid can increase power purchase contract to make up the gap before. By reasonable arrangements of electricity purchase contracts, achieving "compression and compensation" between different months, mainly bases on two factors as follows:

1) The utilization demand of hydropower, wind power, solar energy and other diversified energy.

As the seasons change, generation capacities of hydropower and wind power will be significant fluctuations. To reduce resource waste and emissions, in wet season, the company should maximize purchasing hydropower; in winter and spring, the company should purchase wind resource in priority.

2) Peak regulation demand of inter-provincial spare complementary optimization.

Due to the different levels of economic development, industrial structure, the peak load emergence time of different neighboring provinces varies much. Through the inter-provincial electricity trade, it can achieve peak load shifting and improve economic efficiency effectively.

\subsection{Optimization Model}

Dynamic power purchase between power grids and power plants is a multi-period optimization problem. In order to avoid the disaster of dimensionality problems due to the large size of the system, it needs to decompose the model. The objective optimization function of grid company power purchase is as followed:

$$
\operatorname{Min} \sum_{i=1}^{12} \sum_{j=1}^{N} Q_{i, j} \cdot P_{i, j} \quad i=1,2, \cdots, 12 ; j=1,2, \cdots, N
$$

where:

$Q_{i, j}$ : Electricity to access grid of unit $\mathrm{j}$

$P_{i, j}$ : Generation price of unit $\mathrm{j}$

$N$ : The number of power generation unit

In Formula (1), optimization objective of grid is the lowest annual purchase cost. This is the power grid's total annual target, achieving through the monthly purchase optimization. Assuming that the current month is $\mathrm{n}$, and then purchase outcome of first $n-1$ months is known. Therefore, the formula (1-1) can be further simplified as followed:

$$
\operatorname{Min} \sum_{i=n}^{12} \sum_{j=1}^{N} Q_{i, j} \cdot P_{i, j} \quad i=n, n+1, \cdots, 12 ; j=1,2, \cdots, N
$$

\subsection{Model Decomposition Based on Large-Scale Systems Theory}

Decomposition and coordination of large-scale systems is a method that decomposes the large system into several relatively independent subsystems coordinator. Large systems are usually decomposed into a number of relatively independent but interrelated subsystems, then deals with the extremal points for each subsystem. By the repeated exchange of information between the subordinate, we can obtain the optimal solution of overall system [4] [5]. 
Under inaccurate information, perfect model becomes meaningless. Facing the large-scale systems of electricity purchase optimization, the Formula (2) is further decomposed into the optimization of future monthly electricity purchase:

$$
\operatorname{Min} \sum_{j=1}^{N} Q_{i, j} \cdot P_{i, j} \quad j=1,2, \cdots, N
$$

Power grids can eventually achieve the annual "near-optimal” goal through 11 power purchase local optimizations.

\subsection{Power Purchase Hedging Optimization Model}

Hedging is a kind of trading activity where spot market and future market transact the same commodity, with an equal number but in the opposite direction. It also can construct different combinations to avoid any loss because of future price change [6]. Through the futures market, enterprises get future market information to enhance scientific and rational decision-making and improve economic efficiency of enterprises.

At present, execution of the contract signed by electricity grid and power generation companies needs to meet the condition:

$$
\Delta Q_{i}=0 \quad i=1,2, \cdots, 12
$$

where:

$\Delta Q_{i}$ : Difference between monthly contract and the actual electricity purchase. In other words, contract completion rate of monthly electricity purchase must be $100 \%$.

Under the premise of $100 \%$ annual contract completion ratio, power purchase optimization model presented in this paper, optimizes monthly power purchase program by “Compression and Compensation”. The following conditions are met:

$$
\begin{gathered}
\sum_{i=1}^{12} \Delta Q_{i}=0 \quad i=1,2, \cdots, 12 \\
\left|\Delta Q_{i}\right| \leq Q_{i} \cdot \alpha_{i} \quad i=1,2, \cdots, 12
\end{gathered}
$$

where:

$Q_{i}$ : Monthly electricity contract plan

$\alpha_{i}$ : Permissible deviation of monthly power purchase. The value usually becomes smaller as the end draws near.

Based on the theory of hedging options, monthly electric grid optimization simulation is shown in Figure $\mathbf{1 .}$ When making the monthly purchase decisions, we can change the power purchase plan appropriately, but we must complete the annual contract performance obligations. That means the shaded area above the horizontal axis must be the same as below.

\section{Monthly Power Purchase Optimization Model}

The power sources of provincial power grid generally include: (1) Provincial link lines; (2) Uncontrollable national dispatching and grid dispatching system; (3) Controlled thermal power units; (4) Controlled hydropower units; (5) Provincial electricity trade. Power purchase priority of provincial grid is shown in Figure 2.

As we all know, provincial grid companies can’t control the units power output of type A. So the study object of "Compression and Compensation" is mainly for type B, which provides power purchase space for type C through the power output coordination of Class B. However, under exceptional supply situation, type A can also be regarded as type $B$.

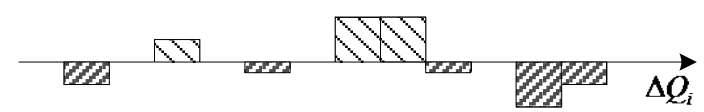

Figure 1. Power purchase optimization simulation based on hedging theory. 


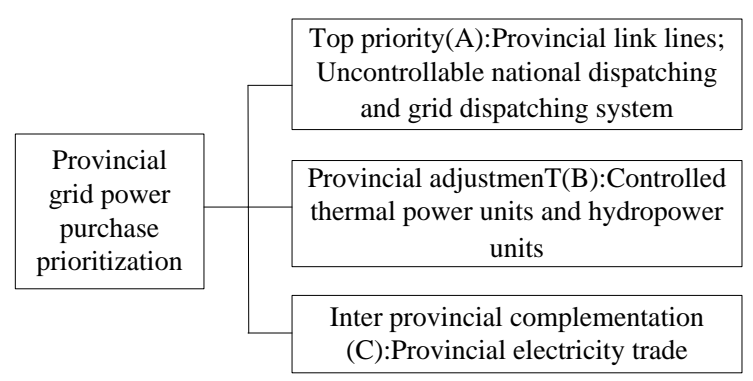

Figure 2. Provincial grid purchase power classification.

\subsection{Prediction and Analysis of Power Balance}

\subsubsection{Rovincial Link Line}

Provincial link line refers to the electricity purchase contract among the provinces through inter-provincial power transmission line at the end of last year. Grids can adjust and compress the monthly purchase plan of provincial link line appropriately to set aside more space for market bilateral trade through "compression and compensation": If the price is higher than that of market bilateral trade, compress the provincial link line to a minimum and purchase low-cost power resources; Else, increase the proportion of provincial link line to make up for the shortfall before.

The maximum capacity that provincial link line can be compressed through "compression and compensation" in month $i$ this year is:

$$
\operatorname{Max} \Delta E_{L, i}=E_{L, i} \bullet \alpha
$$

where:

$\alpha$ : The adjustable range of link line. And the general admission is $\pm 1.5 \%$;

$E_{L, i}$ : Electricity distribution of link line in month $i$. It can be calculated by the following formula:

$$
E_{L, i}=\left(E_{L}-\sum E_{L, i-1}\right) \bullet \beta_{i}
$$

where:

$E_{L}$ : Total electricity of link line;

$\beta_{i}$ : Proportional coefficient of month $i$.

So, the actual electricity purchase of link line this month is:

$$
E_{L, i}^{\prime}=E_{L, i}-\operatorname{Max} \Delta E_{L, i}=E_{L, i}(1-\alpha)
$$

\subsubsection{Uncontrollable National Dispatching and Grid Dispatching System}

Uncontrollable power units include national dispatching and grid dispatching hydropower or thermal power. Generating capacity of such units is allocated to different provinces in certain proportion. Similar to the link line, grids also can adjust and compress the monthly purchase plan to set aside more space for market bilateral trade: If the price is higher than that of market bilateral trade, compress the national dispatching and grid dispatching to a minimum and purchase low-cost power resources; Else, increase the proportion of national dispatching and grid dispatching to make up for the shortfall before.

The maximum capacity that national dispatching and grid dispatching can be compressed through "compression and compensation" in month $i$ this year is:

$$
\operatorname{Max} \Delta E_{G, i}=E_{G, i} \bullet \theta
$$

where:

$\theta$ : The adjustable range of national dispatching and grid dispatching. And the general admission is $\pm 1.5 \%$;

$E_{G, i}$ : Electricity distribution of national dispatching and grid dispatching in month $i$. It can be calculated by the following formula:

$$
E_{G, i}=\left(E_{G}-\sum E_{G, i-1}\right) \bullet \gamma_{i}
$$

where: 
$E_{G}$ : Total electricity of national dispatching and grid dispatching;

$\gamma_{i}$ : Proportional coefficient of month $i$.

So, the actual electricity purchase of national dispatching and grid dispatching this month is:

$$
E_{G, i}^{\prime}=E_{G, i}-\operatorname{Max} \Delta E_{G, i}=E_{G, i}(1-\theta)
$$

\subsubsection{Controlled Thermal Power Units}

Controlled thermal power contracts are signed by grids and generation plants for non-competitive electricity based on the government plan. Different from the two types of power generation plan above-mentioned, this kind of contract has a limit, generally $1.5 \%$, but without an upper limit. To simplify the analysis, we assume that the average generating capacity improvement of the thermal power plants is $10 \%$. If the contract price is higher than that of market bilateral trade, compress the contract to a minimum and purchase low-cost power resources; else, increase the proportion of contract to make up for the shortfall before.

The maximum capacity that controlled thermal power units can be purchased in month $i$ this year is:

$$
\operatorname{Max}_{C, i}=\left(\Delta E_{C}+E_{C} \times 10 \%\right) \cdot \sigma_{i}
$$

where:

$\Delta E_{C}$ : Remaining electricity contract;

$E_{C}$ : Total electricity contract;

$\sigma_{i}$ : Proportional coefficient of month $i$. It can be calculated by the following formula:

$$
\sigma_{i}=L Q_{i} / \sum_{j=i}^{12} L Q_{j}
$$

where:

$L Q_{i}$ : Generation of month $i$ in the previous year.

Similarly, the minimum capacity that controlled thermal power units can be purchased in month $i$ this year is:

$$
\operatorname{Min} E_{C, i}=\left(\Delta E_{C}-E_{C} \times 1.5 \%\right) \bullet \sigma_{i}
$$

\subsubsection{Controlled Hydropower Units}

As a clean energy, power grids should give priority to the hydropower and reduce disposable water. Hydropower is closely related to the water regime. Based on ARMA model, hydropower generation capacity next month is:

$$
Y_{t}=\phi_{1} Y_{t-1}+\phi_{2} Y_{t-2}+\cdots+\phi_{P} Y_{t-p}+\alpha_{t}-\theta_{1} \alpha_{t-1}-\cdots-\theta_{q} \alpha_{t-q}
$$

where:

$Y_{t}$ : The average monthly amount of electricity at a certain time;

$p, q$ : Model order;

$\phi_{1}, \phi_{2}, \cdots, \phi_{p} ; \theta_{1}, \theta_{1}, \cdots, \theta_{q}:$ Model parameters;

$\alpha_{t}$ : Noise interference whose mean is 0 and Variance is $\sigma_{\alpha}^{2}$.

\subsubsection{Maximum Power Purchase Gap}

The maximum power purchase gap is the difference between prediction of annual electricity consumption and other power generation plans compressed. On the other hand, maximum power purchase gap reflects the transaction space of the power grids.

The power purchase space of power grids in month $\mathrm{i}$ is as follows:

$$
S=D_{i}-E_{L, i}^{\prime}-E_{G, i}^{\prime}-M i n E_{C, i}
$$

where:

$D_{i}$ : Electricity consumption prediction

\subsection{Optimization Order of Monthly Electricity Purchase}

\subsubsection{Electricity Balance of Each Month}

Electricity balance from the current month to the end depends on the price, which satisfies the following formula: 


$$
y_{i}= \begin{cases}E_{L, i}+E_{G, i}+\operatorname{Max}_{C, i} & P_{\text {out }, i}>\max \left(P_{L, i}, P_{G, i}, P_{C, i},\right) \\ \min \left(S, \sum E_{\text {out }, i}\right)+E_{L, i}^{\prime}+E_{G, i}^{\prime}+\operatorname{Min} E_{C, i} & P_{\text {out }, i} \leq \max \left(P_{L, i}, P_{G, i}, P_{C, i},\right)\end{cases}
$$

where:

$P_{\text {out }, i}:$ Electricity price of outer provinces;

$P_{L, i}$ : Electricity price of link line;

$P_{G, i}$ : Electricity price of national dispatching and grid dispatching;

$P_{C, i}$ : Electricity price of controlled thermal power unit and hydropower units;

$E_{\text {out }, i}$ : The amount of outer provincial electricity.

\subsubsection{Previous Condition of "Compression and Compensation"}

In the case of power purchase optimization model of grids hedges, the benefits and risks coexist. So, provincial grid companies should strengthen the risks monitoring to achieve risks control effectively. Among them, the most important risk is the risk of contract completion. Therefore, strengthen the inspection of previous "compression and compensation" situation and adjust purchase strategy real-timely to take the "compression and compensation" electricity under control.

By the end of last month, "compression or compensation" electricity of power grids is:

$$
E_{n}=\sum_{i=1}^{n} \Delta Q_{i}
$$

If $E_{n}>\varepsilon_{n+1}$, it means that cumulative compression electricity is more than normal and the electricity contract completion rate is low. The power grids should increase the proportion of the electricity contract;

If $-\varepsilon_{n+1}<E_{n}<\varepsilon_{n+1}$, it means that the strategy of "compression or compensation" is under control;

If $E_{n}<-\varepsilon_{n+1}$, it means that the electricity contract completion rate is higher. The power grids should improve outer-power purchase initiative.

Here, represents the risk judgment threshold of month $n+1$. It depends on risk tolerance capability of power grids. Expert systems can be used to determine a reasonable threshold.

\section{Result and Discussion}

Based on the electricity generation and consumption data of a provincial power grid in 2012, this paper analyzes the implementation effectiveness of power purchase hedge optimization. Average electricity price for all types of contracts is 460.94 Yuan/MWh. The allowable deviation of monthly power purchase contract is $1.5 \%$. In order to ensure the $100 \%$ completion rate, beyond the normal electricity demand, the provincial power grid has to purchases additional 12,753 MWh which is then used for electricity trade in December. The average selling price is 350 Yuan/MWh. The monthly purchase optimization result of this power grid in 2012 is shown in Table 1.

As we can see from Table 1, the benefit of provincial power grid is 9,107,246 Yuan through the electricity purchase hedging optimization in 2012. At the same time, in June, August and September, the proportion of hydropower enhances greatly.

In 2012, electricity purchase optimization results in "compression" period and "compensation" period are shown in Table 2.

From Table 2, it can be seen, in "compression" period, the provincial power grid increases the proportion of hydropower and reduces the consumption level of coal. What's more, the company's earning is increased by 10.52 million Yuan because of the reducing purchase price. Despite a certain amount of economic and environmental cost in "compensation" period, the condition of purchase price and proportion of hydropower develops better than the same period before.

\section{Conclusion}

At present, the provincial power grid usually purchases power resources from outer province passively. Based on hedging theory, this paper proposes a model which makes use of "compression and compensation" strategy to realize the monthly purchase optimization. Through the reasonable implementation of contract plan and pur- 
Table 1. Provincial grid power purchase optimization results in 2012.

\begin{tabular}{cccccc}
\hline Month & $\Delta Q_{i}(\mathrm{GWh})$ & $\begin{array}{c}\text { Purchase price } \\
\text { (yuan/MWh) }\end{array}$ & $\begin{array}{c}\text { Benefit } \\
\left(10^{3} \text { yuan-RMB }\right)\end{array}$ & $\begin{array}{c}\text { Cumulative deviation } \\
(\mathrm{GWh})\end{array}$ & $\begin{array}{c}\text { Proportion of } \\
\text { hydropower }(\%)\end{array}$ \\
\hline 1 & 79.16 & 439.13 & 1726.58 & 79.16 & 16.20 \\
2 & -67.82 & 460.94 & 0 & 11.34 & 16.57 \\
3 & 79.48 & 437.22 & 1885.38 & 90.83 & 16.94 \\
4 & -62.56 & 460.94 & 0 & 28.26 & 17.31 \\
5 & -44.05 & 460.94 & 0 & -15.78 & 18.03 \\
6 & 61.46 & 433.15 & 1707.93 & 45.67 & 21.30 \\
7 & -99.82 & 460.94 & 0 & -54.15 & 19.20 \\
8 & 140.60 & 427.32 & 4726.91 & 86.45 & 22.10 \\
9 & 45.83 & 450.57 & 475.26 & 132.28 & 21.51 \\
10 & -25.38 & 460.94 & 0 & 106.90 & 17.67 \\
11 & -54.13 & 460.94 & 0 & 52.77 & 15.30 \\
12 & -52.77 & 460.94 & -1414.82 & 0 & 15.40 \\
sum & 0 & 455.47 & 9107.25 & 0 & 18.13 \\
\hline
\end{tabular}

Table 2. Power purchase optimization results of “compression and compensation”.

\begin{tabular}{cccccc}
\hline Type & $\begin{array}{c}\text { Electricity adjustment } \\
(\mathrm{GWh})\end{array}$ & $\begin{array}{c}\text { Average deviation of contract } \\
(\%)\end{array}$ & $\begin{array}{c}\text { Hydro proportion } \\
(\%)\end{array}$ & $\begin{array}{c}\text { Revenue } \\
\left(10^{3} \text { yuan }\right)\end{array}$ & $\begin{array}{c}\text { Energy } \\
\text { saving } \\
\left(10^{3} \mathrm{t}\right)\end{array}$ \\
\hline "Compression" & 406.54 & 0.87 & 19.61 & 10522.1 & 118.46 \\
"Compensation" & 406.54 & 0.73 & 17.07 & -1414.8 & -3.72 \\
\hline
\end{tabular}

chasing cheap power resources outside the province timely, power grids can effectively reduce the purchase cost and enhance the company's operating efficiency and environmental benefits.

\section{References}

[1] Liu, Y.-B., Liu, J.-Y. and Tang, J.-M. (2008) An Optimal Decision-Making Model for Power Supply Company’s Power Purchase in Weekly Market Considering Price Elasticity Matrix of Demand Side and Risk. Power System Technology, 32, 18-24,35.

[2] Hu, B.Q., Wang, J.B., Wang, E.Q., et al. (2010) Research on Optimization Purchasing Model for Grid Companies Based on Grid-connected of Pumped Storage Power Station. Water Resources and Power, 28, 149-150,160.

[3] Sheng, F.-Z. and Ji, J.-H. (2007) Study on Optimal Sourcing Strategy of Power Supplier with Option Contract. Power System Technology, 31, 54-57.

[4] Li, C., Song, T. and Xu, F.-Y. (1997) Study of Applying the Large Scale System Decomposition Coordination Theory in Dynamic Dispatching of Power System. Journal of East China University of Technology, 19, 41-47.

[5] Li, A.-L. (1997) A Study on the Large-Scale System Decomposition-Coordination Method Used in Optimal Operation of the Hydroelectric Station System. Water Resources and Power, 15, 58-63.

[6] China Futures Association. Hedging and Arbitrage Trading. China Financial and Economic Publishing House, Beijing. 